\title{
Capital Social e Ensino Superior: Um diagnóstico do capital social entre os docentes do centro universitário UnirG e suas implicações para o contexto local e regional
}

\section{Social Capital and Higher Education: A diagnosis of social capital among teachers of the university center UnirG and its implications for local and regional context}

Alessandra Gomes Duarte Lima1 ${ }^{1}$ Mônica Franchi Carniello²

\section{RESUMO}

O tema capital social, por meio dos laços de confiança e reciprocidade entre grupos, redes e organizações, ganha relevância podendo traduzir-se em fator positivo para o desenvolvimento e o bem-estar social. Nesse contexto, o presente trabalho buscou conhecer, por meio de uma pesquisa descritiva, as características do capital social dos docentes do Centro Universitário UnirG, IES de Gurupi-TO. Utilizou-se como instrumento um questionário, aplicado a uma amostra de 158 professores que teve como referência o Questionário Integrado para Medir Capital Social (QI-MCS), do Banco Mundial. Pela análise das dimensões propostas por Grotaert et al (2003), percebeu-se a presença de baixos níveis de capital social entre o grupo, ao se encontrar frágeis laços de confiança, solidariedade e cooperação, que são o alicerce do capital social, podendo tal fator estar associado à instabilidade do ambiente institucional e também a questões culturais, o que pode comprometer o fortalecimento da IES e sobretudo o contexto local e regional.

Palavras-chave: Capital Social. Ensino Superior. Desenvolvimento.

\section{ABSTRACT}

The theme of social capital through bonds of trust and reciprocity between groups, networks and organizations becomes relevant, which may translate into a positive factor for the development and welfare. In this context, this study sought to ascertain, through a descriptive study, the characteristics of the social capital stock of teachers UNIRG University Center, located in Gurupi-TO. It was used a questionnaire as a tool applied to a sample of 158 teachers and had reference to the Integrated Questionnaire for Measuring Social Capital (SC-IQ), by the World Bank. For the analysis of the dimensions proposed by Grotaert et al (2003) noticed the presence of low levels of social capital among the group, while meeting fragile bonds of trust, solidarity and cooperation, which are the foundation of social capital, this factor may be associated with the instability of the institutional environment as well as cultural issues, which may compromise the strength of this institution and especially the local and regional context.

Keywords: Social capital. High education. Development.

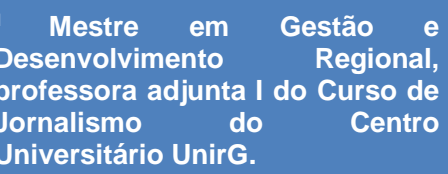

Universitário UnirG.

E-mail: aleduarte@unirg.edu.br

2 Pós-doutora, professora assistente doutora da

Universidade de Taubaté-SP. 


\section{INTRODUÇÁOO}

Nas últimas décadas, mudanças no ambiente econômico mundial têm reacendido o debate sobre os caminhos a serem trilhados a fim de que as populações alcancem melhores padrões de vida, chegando-se à conclusão de que o crescimento da economia não se constitui em desenvolvimento social.

Ocupando lugar de destaque entre as abordagens atuais que tratam sobre os aspectos intangíveis do desenvolvimento, o capital social diz respeito às relações de confiança e reciprocidade que compõem determinado grupo social e que podem gerar benefícios coletivos (D’ARAÚJO, 2010).

O Centro Universitário UnirG está localizado em Gurupi-TO e oferece 15 cursos de graduação em múltiplas áreas do conhecimento. Conta com cerca de 370 professores, entre especialistas, mestres e doutores, residindo ou não no Município, advindos das mais diversas partes do País.

A soma dessas forças, em suas atividades de ensino, pesquisa e extensão, tem significativo peso no contexto local e regional, ao se considerar que o capital social pode ser um importante fator de desenvolvimento.

Emergiu então o tema do presente estudo que buscou conhecer, por meio de uma pesquisa descritiva, as características do capital social existente entre os professores desta IES.

\section{REFERENCIAL TEÓRICO}

\section{Desenvolvimento local e regional: a busca por novos caminhos}

Por um longo tempo o conceito de desenvolvimento esteve atrelado à concepção de crescimento econômico. Entretanto, no decorrer dos anos, constatou-se que somente a vertente econômica seria incapaz de diminuir as desigualdades regionais, aliada à ineficiência do Estado, levantando assim, novas discussões acerca de outros paradigmas para o desenvolvimento (SIMÃO, 2014).

Um desenvolvimento socialmente mais justo, economicamente possível e ambientalmente sustentável ainda é um desafio para as nações, apesar dos esforços para viabilizar um processo equitativo. De acordo com as Organização das Nações Unidas (ONU), a desigualdade nos países em desenvolvimento mostra que $1 \%$ da população mais rica concentra mais de $40 \%$ da riqueza global, e que mais da metade da população pobre 
detém apenas 1\% dos recursos (GARCIA, 2014).

Nessa discussão, tem início então a valorização do território dentro de uma nova perspectiva de desenvolvimento a partir do contexto regional, de modo que as pessoas passam a ter um importante e essencial papel para que haja uma transformação e melhoria da qualidade de vida da comunidade, não apenas do ponto de vista econômico, mas também social e cultural (SAMPAIO; MARINI; PERONDI, 2014). Nesse sentido, emerge o capital social, um ativo intangível que

\begin{abstract}
"...faz-se presente através da relação entre os diversos atores locais, na articulação e no trabalho conjunto de forma sistemática e sinérgica. Quanto maior for essa sistematização e a sinergia, maior será o estoque de capital social dessa região e possivelmente, maiores as condições para o desenvolvimento." (SAMPAIO; MARINI; PERONDI, 2014, p.17).
\end{abstract}

\title{
Capital social: visão teórica
}

Vários autores se dedicam a estudos sobre o tema a fim de analisar os efeitos da ação do capital social no desenvolvimento das comunidades e nações em todo o mundo (D’ARAÚJO, 2010).

Na concepção de Bourdieu (1980), o capital social pode ser entendido como um conjunto de recursos atuais ou potenciais que estão ligados à participação em uma rede constante de relações de interconhecimento e inter-reconhecimento que, de certa forma, são institucionalizadas.

O sociólogo americano James Coleman define capital social como um conjunto de recursos sócio-estruturais que facilitam ações de indivíduos que estão dentro da estrutura. Ao contrário de outras formas de capital, o capital social é inerente às relações entre pessoas, estando 'alojado' nos indivíduos e não em implementos físicos de produção (ÁLVAREZA; ROMANÍ, 2017).

A despeito de Bourdieu e Coleman, Robert Putnam examinou o capital social sob o prisma da cultura cívica e sua relevância para as instituições públicas, indo além das relações meramente grupais. O estudo 'Comunidade e Democracia: A experiência da Itália moderna', realizado na década de 1970 e publicado em 1993, objetivou entender os motivos das disparidades em termos de desenvolvimento envolvendo as regiões norte e sul daquele País (D’ARAÚJO, 2010).

Diante das mesmas condições administrativas, Putnam observou que o norte da 
Itália se desenvolveu mais do que o Sul, concluindo que a diferença se devia principalmente em função da presença do capital social no Norte, considerando que os níveis de civismo, cultura política e as tradições republicanas ali encontradas são fatores essenciais para sua existência (D’ARAÚJO, 2010).

Para Fukuyama, o conceito de capital social relaciona-se aos valores que promovem a cooperação social, de modo que eles estão intrinsecamente ligados às relações sociais e por isso desempenham um relevante papel do ponto de vista econômico. Tais relações são parte da cultura local que "[...] desempenha um papel funcional importante em toda a sociedade, sendo os meios pelos quais os grupos de indivíduos se comunicam e cooperam nas mais variadas atividades" (FUKUYAMA, 2002 apud SIMÃO, 2014, p.25).

\section{As diferentes dimensões do capital social}

De acordo com o Banco Mundial, o capital social subdivide-se em três dimensões, a saber:

- Capital Social de Ligação: deriva de ligações entre pessoas que têm características demográficas semelhantes, como vínculos entre pessoas de uma família, amigos próximos, vizinhos e associações;

- Capital Social de Ponte: configura-se a partir do ajuntamento entre pessoas de distintas origens étnicas ou profissionais, como os vínculos horizontais que ligam pessoas com poderes políticos e status econômicos compatíveis;

- Capital Social de Conexão: é composto pela ligação entre pessoas de classes sociais menos favorecidas e indivíduos que têm posições de autoridade, seja com membros de organizações públicas, como polícia, partidos políticos, ou privadas.

Uphoff (2000) afirma que o capital social pode ser distinguido em duas categorias: estrutural e cognitivo. O capital social estrutural está associado às instituições locais que agem como instrumentos para o desenvolvimento das comunidades, a exemplo dos papéis, regras e procedimentos, bem como as tramas de relações que possibilitam a cooperação e/ou o comportamento cooperativo. Se dá por meio de agregações horizontais e redes sociais com procedimentos de tomada de decisão límpidos, lideranças responsáveis e práticas coletivas.

O capital social cognitivo resulta de processos mentais fortalecidos pela cultura e a ideologia de um grupo, de modo mais específico por normas sociais, valores, atitudes e crenças, que também colaboram para uma conduta cooperativa. Estão incluídas a 
confiança, a solidariedade e a reciprocidade que, se partilhadas entre os componentes do grupo, promovem as condições para que os indivíduos trabalhem em prol do bem comum (UPHOFF, 2000).

\section{MATERIAIS E METODOS}

A pesquisa em questão teve cunho quantitativo no que tange à abordagem, descritivo quanto aos objetivos e quanto aos procedimentos técnicos ou delineamento, consistiu num levantamento.

O universo em estudo foi composto por 340 docentes da IES, sendo que 158 professores compuseram a amostra. Para tal, utilizou-se o cálculo de amostra para populações finitas sugerida por Gil (2008), considerando-se 90\% de nível de confiança e $5 \%$ de margem de erro.

No intuito de permitir que a amostra fosse representativa em relação à população, optou-se ainda por sua estratificação, tendo sido feita proporcionalmente entre as áreas do conhecimento: 23\% dos cursos das áreas de Ciências Sociais Aplicadas/Exatas, 65\% da Saúde e 13\% das áreas de Educação/Licenciaturas. Então, dentro de cada grupo, a amostra foi definida por acessibilidade.

O instrumento da pesquisa teve como referência o Questionário Integrado para Medir Capital Social (QI-MCS), do Banco Mundial, proposto por Grootaert et al (2003). Trouxe 50 questões, entre fechadas e abertas, distribuídas em oito dimensões.

\section{RESULTADOS}

\section{Dimensão Sociodemográfica}

As mulheres são maioria entre os professores da IES, representando $60 \%$ dos pesquisados. A maior parte dos entrevistados tem entre 20 e 40 anos, o que aponta um quadro docente composto por pessoas relativamente novas.

A maior parte dos pesquisados advém de outros estados, especialmente de Goiás (22\%), São Paulo (15\%) e Minas Gerais (13\%), enquanto apenas $20 \%$ do total têm naturalidade tocantinense.

Uma parcela considerável dos docentes reside no Município num período entre seis e 15 anos. Observa-se que 37\% dos entrevistados responderam que o trabalho foi o motivo de mudança para Gurupi. Os especialistas compõem a maior parte do quadro docente da IES: $51 \%$ têm especialização, 23\% são mestres e 3\% doutores. 


\section{Dimensão Trabalho}

Em relação ao tempo de docência no ensino superior, a maioria, $71 \%$, tem entre um e dez anos de experiência, enquanto $40 \%$ afirmam ter entre seis e dez anos. Tais percentuais coincidem com a experiência na UnirG, o que leva a crer que muitos deles iniciaram sua experiência docente no ensino superior na IES, uma vez que $41 \%$ tem entre seis e dez anos de casa e $40 \%$ entre um e cinco anos.

Em relação ao vínculo, $53 \%$ dos docentes são concursados e os contratados somam $47 \%$. Quanto ao regime de trabalho, 56\% trabalham em regime de 40 horas, $23 \%$ com dedicação exclusiva à IES, $16 \%$ com 20 horas e $3 \%$ são horistas.

Em uma das questões indagou se o professor exerce ou não outra atividade além da docência. Do total, $53 \%$ disseram que sim e $42 \%$ que não. A maioria, $75 \%$, tem regime de 20 horas, 40 horas ou é horista, o que permite atuar em outras atividades, enquanto apenas $23 \%$ dos entrevistados trabalham com dedicação exclusiva.

Tais atividades permitem que as redes sejam estendidas para o ambiente externo da IES, possibilitando a prática de suas atividades profissionais, bem como 0 relacionamento com outras organizações. Avista-se aqui, a presença do capital social de ponte, aquele que surge a partir dos laços externos ao grupo original.

\section{Dimensão Grupos e Redes}

Analisar os grupos e redes nos quais os docentes estão inseridos permite conhecer as extensões dessas 'teias', uma vez que, de acordo com Grootaert et al (2003), essa dimensão constitui-se como um dos três indicadores básicos da presença de capital social em um grupo.

Quando perguntados sobre quais grupos integram, os mais citados foram as associações profissionais, os grupos religiosos, educacionais e de saúde. A Associação dos Professores Universitários de Gurupi (APUG) foi o grupo mais lembrado pelos docentes.

Observou-se o pertencimento a grupos diversificados, até mesmo grupos internacionais, a exemplo do Comitê Internacional da Cruz Vermelha e o Greenpace e ainda a participação em grupos voltados à cidadania e ao meio ambiente, em nível local, com menção por parte de alguns professores.

No que concerne aos grupos ligados à docência, observou-se que os professores participam de uma rica gama de grupos internos e externos, nas esferas municipal, 
estadual, federal, nas mais diversas áreas do conhecimento, tais como: Academia Gurupiense de Letras, Associação Brasileira de Fisioterapia em Oncologia, Instituto 3G Inteligência para o Governo Eletrônico, entre outros.

Em relação aos grupos internos, todos estão relacionados a instâncias acadêmicas, em diversos níveis, e também a projetos de pesquisa e extensão e aos estágios. Com referência aos grupos extermos, constatou-se que a maior parte deles está ligada aos cursos de graduação da IES. São compostos por entidades profissionais, associações culturais e literárias, grupos políticos, entidades de saúde, conselhos, grupos de pesquisa, dentre vários outros, que formam uma rica 'teia' de grupos, cuja influência é valiosa para o contexto em estudo, permitindo que informações cheguem à IES e permeiem toda a Instituição.

A maioria dessas redes, entretanto, se dá em âmbito local e regional, percebendose a carência de articulações com grupos de ensino, pesquisa e extensão de outros estados ou mesmo países.

As relações entre os docentes foram avaliadas de forma positiva pela maioria dos pesquisados. As relações profissionais foram melhor avaliadas, pois 39\% classificaram como muito boas, ao passo que $37 \%$ veem as relações de amizade como boas.

A partir da avaliação dessa dimensão constatou-se uma considerável quantidade e variedade de grupos e redes aos quais os docentes da UnirG pertencem.

\section{Dimensão Confiança e Solidariedade}

Esta dimensão diz respeito ao capital social cognitivo e apresenta-se com o segundo tipo básico de indicador para medi-lo. Observou-se um baixo nível de confiança em relação aos diversos grupos que compõem a IES e também aos governos local e estadual.

A Tabela 1 sintetiza os percentuais de confiança nos diversos grupos apontados pela pesquisa, por meio da qual pode-se fazer uma comparação entre eles. Os professores gozam do maior índice de confiança entre os grupos: 39\% confiam muito ou totalmente, seguidos pela Reitoria com 38\% e funcionários, servidores técnico-administrativos, com $33 \%$.

Por outro lado, o governo local têm o maior percentual de desconfiança: 79\% afirmam que confiam pouco ou muito pouco no governo local, seguido pelos membros do governo estadual, com $75 \%$, e a Fundação da IES, com $56 \%$. 
DOI: 10.18605/2175-7275/cereus.v10n4p85-97 Revista Cereus 2018 V. $10 /$ N. 4
LIMA, A. G. D.; CARNIELLO, M. F.

Capital Social e Ensino Superior: Um diagnóstico do capital social entre os docentes do centro universitário UnirG e suas implicações para o contexto local e regional

Tabela 1. Síntese das respostas da dimensão 'Confiança e Solidariedade'

\begin{tabular}{lcc}
\hline \multicolumn{1}{c}{ Grupo } & $\begin{array}{c}\text { Confiam muito/ } \\
\text { totalmente }\end{array}$ & $\begin{array}{c}\text { Confiam pouco/ } \\
\text { muito pouco }\end{array}$ \\
\hline Professores & $39 \%$ & $26 \%$ \\
Funcionários & $33 \%$ & $22 \%$ \\
Alunos & $21 \%$ & $37 \%$ \\
Reitoria & $38 \%$ & $26 \%$ \\
Fundação & $13 \%$ & $56 \%$ \\
Membros do governo local & $3 \%$ & $79 \%$ \\
Membros do governo estadual & $5 \%$ & $75 \%$ \\
\hline
\end{tabular}

Esse baixo nível de confiança entre os grupos pode provavelmente estar relacionado à natureza pública da IES e a alguns momentos institucionais conturbados vivenciados nos últimos anos, gerando certo clima de instabilidade e prejudicando a formação de relações de confiança e cooperação.

Em função de sua natureza pública, a Instituição está ligada à Prefeitura do Município, o que gera uma série de conflitos, uma vez que a Academia escolhe democraticamente seus gestores, a Reitoria e as Coordenações de Curso, mas não os gestores da Fundação que é sua mantenedora.

Nesse caso, a IES não dispõe de autonomia financeira, pois a Fundação que a mantém administrativa e financeiramente é gerida por representantes indicados pelo chefe do Executivo Municipal, com o aval da Câmara Municipal, e é fruto, portanto, e na maioria nas vezes, de uma indicação política, com a constante mudança de gestores.

A ingerência política interfere diretamente na dinâmica da Academia e acaba por gerar uma série de dissabores para a IES, o que talvez esteja associado aos baixos níveis de confiança em relação ao governo local, apontados pela pesquisa, pois suscita um clima de incerteza em relação à gestão.

Ressalte-se que para Putnam (D’ARAÚJO, 2010), a coletividade que valoriza e pratica a confiança, tende a prosperar, produzir o bem comum.

\section{Dimensão Ação Coletiva e Cooperação}

O terceiro conjunto de variáveis é constituído pelos indicadores da ação coletiva (GROOTAERT et al, 2003). Nesta dimensão, observou-se que $77 \%$ dos pesquisados alegam já ter participado de atividades conjuntas em prol dos professores, enquanto $21 \%$ afirmam não ter tomado parte de tais ações.

Quanto aos projetos de pesquisa, a maioria, 68\%, respondeu que não participa, contra apenas 32\% que participam. Em relação aos projetos de extensão $65 \%$ disseram 
que não e 32\% que sim. A maioria diz não participar de atividades comunitárias promovidas pela IES, num percentual de $75 \%$ que disseram não e $24 \%$ asseguram estarem envolvidos, especialmente os professores ligados da área de Saúde.

Observou-se que houve um alto índice de participação em atividades conjuntas em benefício dos professores, mas, a despeito disso, nas demais questões, houve um baixo índice de envolvimento com grupos de pesquisa, extensão e atividades comunitárias.

Alguns fatores podem contribuir para esse cenário, dentre eles políticas de extensão ainda em estruturação; cultura interna volta à pesquisa ainda em germinação, com mais expressão apenas na área de Saúde; falta de uma cultura institucional voltada às atividades comunitárias; e docentes com experiência de mercado, mas pouca vivência da Academia. Isso reforça alguns aspectos já mencionados anteriormente, como a concentração de esforços no ensino, mas a falta de uma cultura sólida com respeito à extensão e à pesquisa, o que pode comprometer o amadurecimento da IES enquanto centro universitário.

\section{Dimensão Informação e Comunicação}

Esta dimensão constitui-se como um relevante parâmetro para medição do capital social, haja vista que a habilidade de seus membros em se comunicarem contribui para sua manutenção. Nesta questão, os professores deveriam indicar as fontes mais utilizam para se informar sobre o que ocorre na IES. Os três meios mais lembrados foram o site da IES, as conversas com colegas e os e-mails.

\section{Dimensão Coesão e Inclusão Social}

O nível de coesão e inclusão social apresenta-se como um das manifestações positivas da existência de capital social em um grupo, bem como pela frequência de interações sociais do cotidiano (GROOTAERT et al, 2003).

Quando perguntados como vêem as relações entre os professores, para 32\% são 'Relativamente distantes', 28\% 'Relativamente próximas', 14\% 'Muito distantes' e apenas $1 \%$ 'Muito próximas'.

Os pesquisados apontaram como principais entraves às relações a pouca proximidade com os colegas e a falta de incentivos e desconfiança. Citaram ainda: aacomodação; distanciamento entre os cursos e áreas da IES; falsidade; falta de ambientes e mecanismos que propiciem maior aproximação; falta de comprometimento com as atividades interdisciplinares; falta de envolvimento emocional e comprometimento com a IES; falta de motivação coletiva; falta de oportunidades de socialização; inexistência de 
núcleos de pesquisa em algumas áreas; interesses pessoais diferentes, dentre outros.

Sobre o grau de cooperação, a pesquisa apontou que há um maior grau entre os professores do próprio curso, com avaliação positiva de $71 \%$, do que entre professores da Instituição de modo geral, em que 57\% avaliaram positivamente.

Quanto à classificação do grau de cooperação entre os professores do curso, 33\% classificaram como bom; $23 \%$ muito bom; $9 \%$ ótimo; $6 \%$ excelente; $24 \%$ regular; $3 \%$ ruim e $1 \%$ péssimo.

Em referência ao grau de cooperação entre todos os professores da IES, 43\% classificaram como bom; $9 \%$ muito bom; $4 \%$ ótimo; e 1\% excelente; $34 \%$ regular; $7 \%$ ruim e $1 \%$ péssimo.

Percebeu-se um maior grau de cooperação entre os professores do próprio curso do que em relação aos da IES de modo geral, o que é natural uma vez que a proximidade e os encontros periódicos favorecem os laços e não há encontros frequentes entre todos os professores.

Se o grau de coesão e inclusão social se apresentam como resultados positivos do capital social, pode-se então inferir, à luz de Grotaert et al (2003), que não há presença de capital social ou que se dê em baixos níveis, considerando: a distância nas relações vista pela maioria; as barreiras apontadas pelos pesquisados como impecilhos para um melhor relacionamento; o nível mediano de cooperação entre os professores e a baixa frequência de interações cotidianas.

\section{Dimensão Autoridade ou Capacitação (Empowerment) e Ação Política}

Grootaert et al (2003) definem autoridade ou capacitação (Empowerment) como a capacidade de os indivíduos tomarem decisões que estejam ligadas às suas atividades do cotidiano e que podem modificar o rumo de suas vidas, enquanto a ação política se caracteriza como um dos meios que possibilitam o aumento desse Empowerment. Assim como a 'Coesão e Inclusão Social', essa categoria é vista como resultado da presença do capital social em um determinado grupo.

$\mathrm{Na}$ presente pesquisa foi apresentada uma escala de felicidade pessoal. Entre os entrevistados $51 \%$ se consideram muito felizes, enquanto $44 \%$ se avaliam como moderadamente felizes. Ninguém se classificou como muito infeliz. Em relação ao poder que sentem em relação às decisões importantes, aquelas que são capazes de mudar o curso de suas vidas: $47 \%$ se julgaram geralmente capazes e $44 \%$ totalmente capazes.

Observou-se que a maioria dos entrevistados sente que têm capacidade, que pode 
contribuir para que a IES seja um local melhor para se trabalhar, sendo que $38 \%$ disseram ter um médio impacto e 36\% um grande impacto.

Embora seja algo abstrato, e muitas vezes faltem ferramentas e poder decisório para tal, talvez isso demonstre uma certa disposição em buscar soluções para os problemas da IES, levando em conta que os professores são a força motriz de uma instituição de ensino superior.

O exame das seis dimensões, tendo como referência Grootaert et al (2003), indicam uma reduzida presença de capital social: três apresentaram indícios positivos e três negativos. Entre os negativos estão as dimensões Confiança e Solidariedade e Ação Coletiva e Cooperação que, de acordo com os autores, estão entre as medidas básicas para mensuração de capital social.

Percebe-se a tendência de não se confiar nas pessoas dentro da IES e também de pouco envolvimento em atividades conjuntas. Assim, entre os três indicadores básicos, apenas a dimensão Grupos e Redes mostrou-se positiva. Nesse caso, foi o que se percebeu de mais rico entre os docentes: a gama de grupos dos quais participam em nível local, regional, nacional e até internacional.

A dimensão Coesão e Inclusão Social mostrou-se desfavorável, destacando-se a distância nas relações entre os professores, as barreiras apontadas pelos pesquisados como empecilhos para um melhor relacionamento: o nível mediano de cooperação e a baixa frequência de interações cotidianas entre eles.

Ressalta-se que na dimensão Informação e Comunicação houve um saldo positivo, o que é relevante, pois a habilidade de comunicar entre os membros que compõem o grupo permite a manutenção e o reforço do capital social.

A última dimensão, Autoridade e Capacitação (Empowerment) e Ação Política, aparece como resultado da presença de capital social e deu indicações de ser positiva.

\section{CONSIDERAÇOES FINAIS}

A partir da premissa que o capital social é uma das variáveis que pode contribuir para o desenvolvimento regional, a presente pesquisa buscou conhecer as características do capital social existente entre os docentes do Centro Universitário UnirG.

O estudo apontou uma baixa presença de capital social com destaque para a falta de confiança entre os grupos que a compõem, permitindo um delineamento do perfil institucional sob a ótica dos docentes da IES. A baixa presença deste ativo pode se dever 
DOI: 10.18605/2175-7275/cereus.v10n4p85-97
LIMA, A. G. D.; CARNIELLO, M. F.

Capital Social e Ensino Superior: Um diagnóstico do capital social entre os docentes do centro universitário UnirG e suas implicações para o contexto local e regional

à falta de confiança, reciprocidade e cooperação entre os grupos, fatores estes que são a base do capital social. Tal cenário provavelmente esteja relacionado ao ambiente conturbado vivido pela IES nos últimos anos, advindo, na maioria das vezes, de conflitos com os poderes Executivo e Legislativo do Município.

Essa carência também pode estar associada ao histórico cultural do Estado, marcado pelo clientelismo e relações de poder fortemente influenciadas por interesses políticos, 0 que vai ao encontro dos postulados de Bandeira e Putnam para os quais o capital social estaria ligado à questões culturais. Surge, entretanto, outro questionamento: tal fato não deveria ser diferente já que se trata de um grupo composto, em maioria, por indivíduos advindos de outros Estados e portanto, de outras culturas? Mas isto já seria ponto para um novo estudo.

A sua falta pode ser prejudicial à Instituição, pois enfraquece os professores na busca por interesses comuns e melhoria de condições para a própria Instituição, uma vez que as relações e ações podem fazer a diferença diante do contexto local e regional, que enfrenta as disparidades sociais, econômicas e culturais inerentes à região Norte do Brasil.

Cabe aos docentes e aos gestores dimensionarem a importância desse ativo intangível não só para o fortalecimento da IES como para toda a região, buscando caminhos possíveis para o entendimento entre os corpos docente, discente e administrativo e os membros da gestão municipal no sentido de solucionar os conflitos e consequentemente contribuir para o reequilíbrio institucional.

Para concluir, ficam as afirmações de Putnam e Fukuyama, para os quais a confiança tem papel preponderante para a prosperidade de uma nação e são o alicerce do capital social. Para eles, as oportunidades são mais bem aproveitadas e há mais colaboração quando se sente e sabe que se pode confiar. Assim, poder confiar nos outros, se torna um importante fator de desenvolvimento.

\section{REFERENCIAS}

ÁLVAREZA, E.C.; ROMANÍ, J.R. Measuring social capital: further insights. Gaceta Sanitaria. Volume 31, Issue 1, pages 57-61, Spain, 2017. Disponível em: < https://reader.elsevier.com/reader/sd/D297878E628C678DEA76BF74206F382C27D42C9 150B838086C8B9291C5D90F28E48D616C853072232F2C9111E59361E3>. Acesso em: 20 ago. 2018.

BANCO MUNDIAL. Relatório sobre o Desenvolvimento Mundial: o Estado em um Mundo em Transformação. Washington, DC: Oxford University Press, 1997. Disponível em: <http://econ.worldbank.org/external/default/main?pagePK=64165259 
DOI: 10.18605/2175-7275/cereus.v10n4p85-97 Revista Cereus
LIMA, A. G. D.; CARNIELLO, M. F.

Capital Social e Ensino Superior: Um diagnóstico do capital social entre os docentes do centro universitário UnirG e suas implicações para o contexto local e regional

\&theSitePK=477960\&piPK=64165421\&menuPK=64166093\&entityID $=000090341200705$ 22125737>. Acesso em: 12 nov.2011.

BANDEIRA, P. Participação, Articulação de Atores Sociais e Desenvolvimento Regional. Texto para discussão n. 630. Brasília: IPEA, 1999.

BOURDIEU, Pierre (1980). O Capital Social - Notas Provisórias. In: NOGUEIRA, Maria Alice e CATANI, Afrânio (org.). Escritos de educação. Petrópolis: Vozes, 1998. p. 67

D’ARAÚJO, M. C. Capital Social. 2. ed. Rio de Janeiro: Zahar, 2010.

FUNDAÇÃO E CENTRO UNIVERSITÁRIO UNIRG. Manual da Pesquisa. Pró-reitoria de Pesquisa e Pós-graduação. Gurupi, 2010. Disponível em: <http://www. pos.unirg.edu.br/index.php?ctt=Usu manual.php>. Acesso em: 10 nov. 2010.

FUNDAÇÃO E CENTRO UNIVERSITÁRIO UNIRG. Plano de Desenvolvimento Institucional, 2012-2016. Gurupi, 2011, 147p. Disponível em: <http://www.unirg. edu.br/reitoria/pdf/pdi.pdf>. Acesso em: 20 dez. 2011.

FUNDAÇÃO E FACULDADE UNIRG. Plano de Desenvolvimento Institucional, 2007. Gurupi, 2007, 69p. Disponível em: <http://www.unirg.edu.br>. Acesso em: 05 set. 2011.

GARCIA, Júnior. Desigualdade, pobreza e os mais ricos. Laboratório de Demografia e Estudos Populacionais. Juiz de Fora, fevereiro de 2014. Disponível em: $<$ http://www.ufjf.br/ladem/2014/02/28/desigualdade-pobreza-e-os-mais-ricos-artigo-dejunior-garcia/>. Acesso em: 20 ago.2018.

GIL, A.C. Métodos e Técnicas de Pesquisa Social. 6. ed. São Paulo: Atlas, 2008.

GROOTAERT, C. et al. Questionário Integrado para Medir Capital Social (QI-MCS). Washington, DC: Banco Mundial, 2003.

IBGE. Instituto Brasileiro de Geografia e Estatística. Disponível em: <www.ibge.gov. br> Acesso em: 05 mar.2011.

SAMPAIO, G.C.; MARINI, M.J.; PERONDI, M.A. Capital Social e Desenvolvimento Regional: uma Revisão Bibliométrica. In: Congresso Nacional de Pesquisas em Ciências Sociais Aplicadas, 3., 2014, Francisco Beltrão-PR. Disponível em: $<$ http://cacphp.unioeste.br/eventos/conape/anais/iii conape/Arquivos/Artigos/Artigoscompl etos/CIENCIASECONOMICAS/9.pdf>. Acesso em: 22 ago.2018.

SIMÃO, G. L. Capital Social e Desenvolvimento Local: Análise do Programa de Aquisição de Alimentos (PAA) em Quatro Municípios da Zona da Mata de Minas Gerais. Dissertação de mestrado. Universidade Federal de Viçosa, 2014. Disponível em:<http://www.locus.ufv.br/bitstream/handle/123456789/1994/texto\%20completo.pdf?seq uence $=1>$. Acesso em: 20 ago.2018.

UPHOFF. N. Understanding Social Capital: Learning from the Analysis and Experience of Participation. In: DASGUPTA, P.; SERAGELDI, I. (org.) Social Capital: A Multifaceted Perspective. Washington, D.C.: World Bank, 2000. Disponível em: $<$ http://scholar.google.com.br/scholar?q=\%E2\%80\%9CUnderstan ding+Social+Capital:+learning+from+the+Analysis+and+Experience+of+Participation\&hl=p t-BR\&as sdt=0\&as vis $=1 \&$ oi=scholart $>$. Acesso em: 12 nov.2011. 